\title{
LOS SECANOS DE HERBÁCEOS DEL INTERIOR PENINSULAR: APUNTES PARA UNA
} ESTRATEGIA

\author{
$\underline{\text { Alicia Langreo Navarro }}{ }^{\mathrm{a}}$ y Tomás García Azcárate ${ }^{\mathrm{b} *}$, \\ ${ }^{a}$ Directora de Sabora, S.L. E-mail: alangreonavarro@gmail.com ${ }^{b}$ Vice-Director del Instituto de \\ Economía, Geografía y Demografía (IEGD-CSIC) e investigador asociado del CEIGRAM, Madrid, E- \\ mail: tomasgarciaazcarate@gmail.com
}

Resumen: Nuestra contribución se centra en las zonas de secano destinados a cultivos herbáceos y barbechos y, en particular, en particular los que se encuentran por encima de los 600 metros de altitud, lo que condiciona sobremanera su aprovechamiento agrario. Coinciden en buena medida con las áreas con mayores problemas demográficos de España.

En esta comunicación se analizan los problemas estructurales y de organización del cultivo y del trabajo en estas áreas y se realizan una serie de propuestas de cara a lograr el mantenimiento del cultivo de forma sostenible tanto medioambiental como económica y socialmente. La magnitud del problema, su implicación con los territorios despoblados, su vinculación a la ganadería y su importancia medioambiental nos lleva a concluir en la necesidad de una reflexión global que desembocara en la elaboración de un Plan Estratégico para los secanos dedicados a los cultivos herbáceos, que debería ser fruto del gran consenso político y social necesario para abordar el desafío de la España vaciada..

Palabras claves:_secanos, sostenibilidad, políticas públicas

\section{Introducción}

Nuestra contribución se centra en los secanos destinados a cultivos herbáceos y barbechos, que suman 9.721.377 hectáreas (el 57,65\% de la superficie cultivada) y, en particular, en particular los que se encuentran por encima de los 600 metros de altitud, lo que condiciona sobremanera su aprovechamiento agrario. Están ubicados prioritariamente en las dos Castillas y Aragón y en ellos las condiciones agroclimáticas determinan que tengan rendimientos muy variables y muy inferiores a los de otros países de la UE.

Las zonas de secano dedicadas prioritariamente a herbáceos coinciden en buena medida con las áreas con mayores problemas demográficos de España, lo que es coherente con la escasa capacidad de arrastre de actividad de los sistemas de producción prioritarios en ellas. Por otro lado, el mantenimiento de estos cultivos tiene una gran importancia medioambiental. Lamentablemente existen pocos análisis económicos de esta realidad.

Los otros grandes usos de las tierras de secano, olivar, viña y frutos secos cuentan con planes estratégicos o medidas de apoyo específicos. Sobre ellos se han realizado numerosos estudios e informes. También tienen mecanismos como las Denominaciones de Origen, muy escasas en las producciones de los cultivos herbáceos de secano, con excepción de las legumbres, y cuentan con producciones marquistas que permiten más estrategias empresariales en la cadena de producción.

En esta comunicación analizaremos los problemas estructurales y de organización del cultivo y del trabajo en estas áreas y realizaremos una serie de propuestas de cara a lograr el mantenimiento del cultivo de forma sostenible tanto medioambiental como económica y socialmente.

\section{Metodología}

Este trabajo es una reflexión basada en la experiencia de los autores en el análisis de la economía agraria y alimentaria española y en la política agraria europea (Langreo Navarro y García Azcárate, 2019) como una revisión de la escasa bibliografía existente, entre la que destacan Sancho Comíns y Navalpotro Jiménez (1995) y Serrano Bermejo y al (2005, 2008).

Asimismo ha sido útil el debate con responsables de cultivos herbáceos de las organizaciones representativas de la cadena de producción de cereales y oleaginosas, los debates en el seno de la Asociación de Técnicos Cerealistas y en el Foro Agrario. Igualmente hay que citar el debate generado en la elaboración del Capítulo de Estructuras del Libro Blanco de la Agricultura y la Alimentación (MAPA 2003). Por 
último, hemos podido realizar 10 entrevistas utilizando la metodología conocida como "de la bola de nieve".

\section{La problemática}

Conscientes de los límites de nuestra contribución, vamos a abordar aquí dos de los elementos que consideramos más importantes: las condiciones naturales bajos y las deficiencias en la estructura productiva.

Los rendimientos en la zona de estudio no solo son bajos, aunque se haya producido una cierta mejoría sobre todo en las mejoras zonas, sino irregulares al depender básicamente de la pluviometría en otoño y primavera. Una gran parte de estas superficies cumple un papel medioambiental esencial en el mantenimiento de la fauna (aves esteparias, áreas Zonas Especiales de Protección de Aves ZEPAs,..). Aunque tanto las leguminosas como los cereales arrastren menos actividad económica que otros sectores agropecuarios, son importantes para un tejido económico normalmente particularmente débil.

Otra gran cuestión a tomar en consideración es la estructura empresarial y el capital humano con el que cuentan. La existencia de muchas explotaciones lleva consigo una escasa dedicación de los agricultores, su envejecimiento y una pequeña capacidad de innovar. Ello ha favorecido el desarrollo de empresas de servicios y la externalización de parte de (o incluso todas) las labores.

\section{Las políticas públicas}

La agricultura de secano es la gran olvidada de la política agraria española, no solo de los responsables políticos sino también, en buena medida, de los sindicales y de los investigadores académicos, en contraste con la virulencia de los debates sobre el regadío, la política hidráulica y los trasvases. Como muestra bien puede valer los resultados de unas búsquedas en Google. A la pregunta "agua, agricultura, España" aparecen 71,3 millones de respuestas; Cuando se sustituye la palabra "agua" por la de "secano", las referencias descienden a 652.000 .

Hay muy pocas excepciones en este panorama desolador, concretamente tres que sepamos. Las dos primeras están en relación directa con la primera de las grandes reformas de PAC, la conocida como reforma Mac Sharry (1992): el método de cálculo de las ayudas compensatorias y otra con la retirada de tierras. La tercera tiene que ver con el pago verde introducido en la versión actual de la PAC.

Por razones de espacio, solo desarrollaremos esta última. Las instancias europeas han favorecido la diversificación de cultivos y los cultivos proteicos, en el marco de la PAC actual. Este ha tenido un efecto derivado positivo para el secano español., que se viene a sumar a los efectos positivos de dos medidas complementarias. La primera es la autorización de usar cultivos fijadores de nitrógeno para la justificación de las Superficies de Interés Ecológico (FEGA, 2020). La segunda es la posibilidad para un Estado miembro, de la que España ha hecho uso, de dedicar hasta un $2 \%$ adicional al techo máximo autorizado para las ayudas acopladas para un apoyo vinculado a este tipo de cultivos.

\section{Algunas propuestas para el debate}

Existen otras zonas en el mundo (como Australia y a algunos estados centrales de los Estados Unidos) con condiciones agroclimáticas similares a las de nuestras áreas áridas. Allí, el cultivo no solo es posible, sino que se desarrolla con unos niveles de rentabilidad aceptables. Allí los impuestos sobre la energía, que supone un gran capítulo de los gastos, son menores; aplican unas técnicas de cultivo que mejoran sus rendimientos aprovechando mejor los insumos y reduciendo sus costes al haber generalizado, entre otros, la agricultura de conservación y la agricultura de precisión; disponen de semillas adaptadas a sus suelos áridos; realizan tratamientos del suelo encaminados a mejorar el metabolismo del nitrógeno; la gestión del agua es una prioridad de primer orden que disfruta de un gran consenso político y han avanzado decididamente hacia una agricultura de precisión. Todo esto se ve, además, favorecido por una mejor estructura empresarial y una puesta en mercado más eficiente.

La primera necesidad que hemos identificado es la importancia de mejorar el conocimiento de lo que realmente está aconteciendo en esos grandes territorios que son los secanos españoles considerados en su conjunto. Los campos a abordar son amplios, pero nos permitimos destacar la situación real de las estructuras de gestión de las explotaciones, que es bien distinta de la estructura de la propiedad o de los beneficiarios del pago básico de la PAC. 
La magnitud del problema, su implicación con los territorios despoblados, su vinculación a la ganadería y su importancia medioambiental nos lleva a plantear la necesidad de una reflexión global que desembocara en la elaboración de un Plan Estratégico para los secanos dedicados a los cultivos herbáceos, que debería ser fruto del gran consenso político y social necesario para abordar el desafío de la España vaciada.

Un pilar importante de este Plan debería ser la mejora de las estructuras de las explotaciones. Se trataría de favorecer todos los mecanismos que promuevan la concentración de la gestión de las explotaciones, asegurando la propiedad, aprovechando incluso el fenómeno de la externalización de tareas y de la gestión. La futura PAC y, en particular la figura del "agricultor genuino" que se puede (y se debe) definir en el marco del Plan Estratégico Nacional abre una oportunidad interesante que no se debería desaprovechar.

El Pacto Verde, las estrategias "De la Granja a la mesa" y "Biodiversidad" requieren la necesaria movilización proactiva de los agricultores. El asesoramiento de las explotaciones (Moyano, 2019) y unos potentes Eco-esquemas, junto con el salto tecnológico que estamos viviendo, son piezas importantes.

Los secanos españoles son víctimas, en cuanto al cálculo de las ayudas directas que les corresponde hoy, de cómo se han aplicado en España las distintas fases de su implantación. Los rendimientos históricos, las hectáreas elegibles, los derechos históricos, el coeficiente de admisibilidad de pastos, son obstáculos que se erigen en el camino de unas ayudas directas que se postulan a ser "para la sostenibilidad". Si quien más recibe es quien más ha producido en el pasado, no puede ser compatible con ayudar a quien más lo necesita para mantener una agricultura activa y sostenible sobre el conjunto del territorio. De nuevo el Plan Estratégico nacional, con una nueva regionalización del apoyo público a la agricultura, tiene una importancia capital.

Desde el ángulo de la cadena, cabe pensar en una segmentación estratégica que permita capitalizar mercados como el creado por el resurgir de las panaderías artesanales y la nueva norma del pan; en el fomento de las leguminosas forrajeras o el aumento de los consumidores vegetarianos.

El devenir de los secanos españoles está también relacionado con la ganadería. La complementariedad con la ganadería extensiva no necesita explicaciones. Pero también la ganadería intensiva, primera cliente de la cebada característica de estos secanos, puede formar parte de la solución. Esta ha demostrado una notable capacidad de adaptación la que ha faltado a la Administración para transcribir correctamente la Directiva nitratos al derecho español y vigilar su estricto cumplimiento, para evitar los problemas de coexistencia que estamos observando actualmente. Tema distinto es la burbuja porcina a la que estamos asistiendo y que pasará cuando China recupere sus niveles de producción.

Nuestra visión incorpora más variables como, por ejemplo, los cultivos emergentes como las trufas; las huertas del interior; las energías renovables, la potenciación del autoconsumo energético; las actividades turísticas o las cinegéticas.

Por último, este Plan debería integrase en la respuesta al desafío de la España vaciada. El desarrollo Rural, por un lado, y los fondos "Next Generation" son dos palancas que deben acabar con la brecha digital y abordar el abandono escolar y sanitario, de servicios (incluido los bancarios) y la incomunicación resultante de décadas de recortes presupuestarios y de "racionalidad" económica a corto plazo.

\section{Bibliografía}

FEGA (2019): Informe sobre la aplicación del pago para prácticas beneficiosas para el clima y el medio ambiente (pago verde) CAMPAÑA 2019. https://www.fega.es/es/noticias/node-53119

Langreo Navarro, A.; García Azcárate, T. (2019): ¿Qué actividad en la España Vacía?

Economía Agraria y Recursos Naturales, 19 (1): 09-15

Moyano, E. (2019): ¿Tiene sentido hablar de extensión agraria en pleno siglo XXI? Eldiariorural.es http://eldiariorural.es/tiene-sentido-hablar-de-extension-agraria-en-pleno-siglo-Xxi/

Sancho Comíns. J. y Navalpotro Jiménez, P. (1995): La extensificación de los secanos herbáceos españoles: efectos territoriales y sociales de la nueva PAC de la Unión Europea Estudios Geográficos, 221: 737-759 
Serrano, A.; Suárez de Cepeda, M.; Sánchez-Girón, V. (2008): Rentabilidad económica de explotaciones agrarias de secano según tamaño y tipo de laboreo Economía Agraria y recursos Naturales, 8(2): 73-91 